\section{Drug price deal spells windfall for researchers}

Xavier Bosch, Barcelona

Biomedical researchers in Spanish universities and hospitals are to receive a large cash injection from the pharmaceutical industry - in exchange for a promise from the government that it will not tighten price controls on drugs.

The unusual agreement will deliver US\$275 million over three years to the health ministry's research agency, the Instituto de Salud Carlos III (ISC). This figure almost matches the $\$ 130$ million a year that the Spanish government currently spends on biomedical research.

The announcement, made on 31 October, has been warmly welcomed by researchers. But although the money is supposed to come with no strings attached, some scientists have already expressed reservations that industry may influence how it is spent - and that the ISC may not distribute it efficiently.

The agreement is intended to ease the tension between the government and Farmaindustria, a body that represents 300 drug companies. Relations between the two have been strained since the health ministry lowered the caps that it imposes on drug prices by $6 \%$ in 1999.

In return for a promise from the government not to lower prices again, the industry will give the money to the ISC for "cancer, cardiovascular and genomics research". The industry also pledges to raise its annual budget for clinical trials conducted in public hospitals from $\$ 80$ million to $\$ 135$ million.

Of Spain's current investment in biomedical research, only about $\$ 20$ million comes from grants at the ISC. The agency has been supported by Farmaindustria before - last year it received $\$ 30$ million from the industry group to help build the Spanish National Cancer Centre (CNIO) and the Institute of Cardiovascular Diseases (IICV), both of which are under construction in Madrid (see Nature 406, 550; 2000).

The health ministry says that it has not decided exactly how to distribute the new funding. But some officials say that onethird of it will go to the CNIO, the IICV and genomics and proteomics research, with the rest going out as grants to research groups in public hospitals, and to support the training of researchers.

The government has rejected Farmaindustria's suggestion that a panel representing both parties should manage the money, and the industry is to set up its own panel to monitor how it is spent.

\title{
Disputed diagnoses hamper claims of mercury poisoning
}

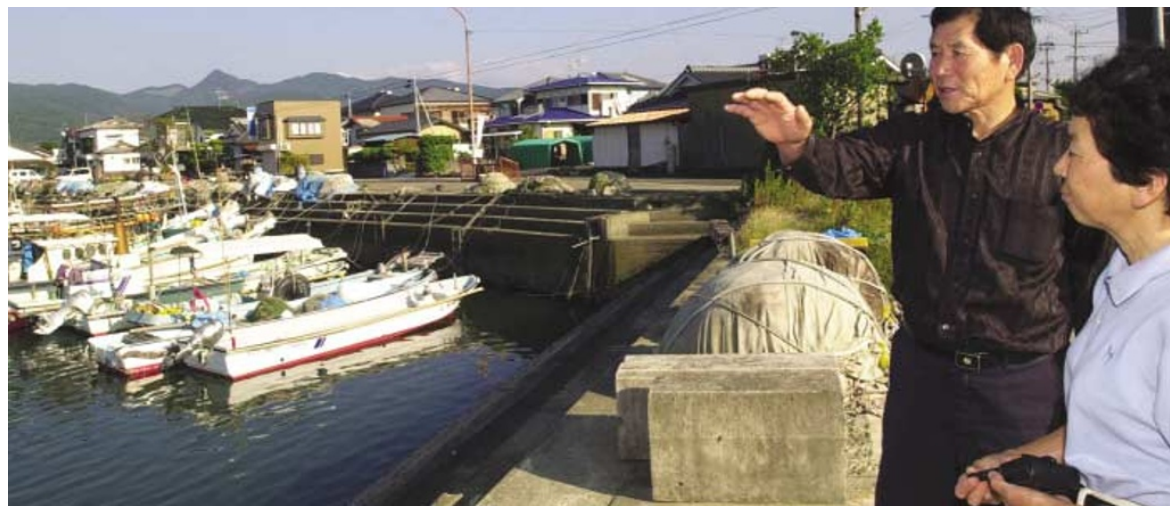

Deadly backwash: although now clean, Minamata Bay was a source of heavy mercury pollution.

\section{David Cyranoski, Tokyo}

A controversy over mercury poisoning that has dogged the Japanese government for nearly 50 years shows little sign of abating.

Minamata disease, a nervous disorder caused by methyl-mercury poisoning, was first identified in 1956. But at the sixth International Conference on Mercury as a Global Pollutant, held in Japan last month, experts were still arguing over how to diagnose the condition.

The waters around Minamata, a small town on the southern island of Kyushu, had been polluted since the 1950s with effluent containing mercury compounds from a chemical plant run by the company Chisso. Ever since the first cases of Minamata disease were identified, the issue of how victims should be compensated has caused the Japanese government problems.

A compensation scheme was finalized in 1995 , offering victims certified as having the disease $¥ 2.6$ million (US\$21,000) on the condition that they make no further claims and absolve the government of blame.

But some sufferers did not accept these terms and continued with their claim. And in April this year, the Osaka high court ordered the government and Chisso to pay US\$2.65 million to 51 plaintiffs who say they have the disease. The government is now appealing against this decision in the Supreme Court.

Minamata disease starts with numbness in the limbs, and progresses to slurred speech, hearing and vision disabilities, loss of coordination and, for many, death.

For years, one of the main tests for the disease gauged a patient's ability to register touch. A doctor would brush the tip of a patient's finger with a certain amount of pressure to see whether the patient could feel it.

But Shigeo Ekino, an anatomist at Kumamoto University, argues that such tests cannot distinguish between peripheralnerve damage and damage to the central nervous system, which the disease initially affects. Ekino's own research, presented at the meeting, uses a more sophisticated, twopoint test in which two nearby spots on the finger are 'poked' with thread-like filaments.

Ekino, who gave evidence in the Osaka court case, believes that the government has underestimated the number of people suffering from the disease and that the true number could run into tens of thousands.

"The government's previous ways of judging whether someone was suffering from Minamata disease were unscientific and overlooked many victims," says Ekino, whose study compared residents of a fishing village on the same sea as Minamata with a control group in a similar village elsewhere in Japan.

But Akihiro Igata, director of the Aichi Comprehensive Health Science Center, who supervised the original testing of Minamata victims and was on the government's council for environmental health until January 2001, defends the old judgements. "We also did two-point discrimination tests, but we found no major difference," he says.

Ekino argues that Igata's tests were not sensitive enough. People who have suffered quite severe damage can distinguish poking with two filaments that are one or two centimetres apart, he says, but when the distance between them is reduced to about 3 millimetres, only those who have suffered damage to the central nervous system are unable to sense two distinct stimuli. The results of the debate could affect compensation claims by thousands of residents who are still applying for certification as Minamata victims.

Ekino also wants new surveys to establish the true extent of the disease, and claims that the government is not releasing data on mercury levels that it has already gathered. Environmental groups, meanwhile, are also pressing for the government to conduct health surveys and to give relief to Minamata victims in light of the new findings. 